\title{
Correction to: Coviability of Social and Ecological Systems: Reconnecting Mankind to the Biosphere in an Era of Global Change
}

Olivier Barrière, Mohamed Behnassi, Gilbert David, Vincent Douzal, Mireille Fargette, Thérèse Libourel, Maud Loireau, Laurence Pascal, Catherine Prost, Voyner Ravena-Cañete, Frédérique Seyler, Serge Morand

\section{Correction to:}

\section{The Frontmatter in : General Introduction}

O. Barrière et al. (eds.), Coviability of Social and Ecological Systems: Reconnecting Mankind to the Biosphere in an Era of Global Change, https://doi.org/10.1007/978-3-319-78497-7

The original version of the book was inadvertently published with surname and first name of the authors interchanged in the Reference section of the General Introduction in the front matter. This has now been corrected. 